\title{
CRISE NA LEITURA E FORMAÇÃO DE LEITORES: UMA QUESTÃO DE POLÍTICA LINGUÍSTICA?
}

Cristina Vergnano-Junger

(UERJ)

\section{RESUMO}

Vários pesquisadores, agentes governamentais e de avaliação de formação têm posto em pauta o que vem sendo chamado "crise na leitura" no Brasil. Aliadas a isso, surgem as reflexões sobre a formação de leitores e do consequente papel da escola nesse cenário. Igualmente, as tecnologias digitais e a internet, com seus textos e linguagens específicos, são associadas com frequência ao problema. Nos últimos anos vimos dedicando-nos aos estudos relacionados à compreensão leitora, com foco na sua relação com o mundo digital. E, embora o tema da crise leitora seja muito discutido no âmbito da educação, nossa abordagem apoia-se em pressupostos da sociocognição, dentro dos estudos em Linguística Aplicada. Nesse sentido, propomos neste artigo abordar o tema sob uma ótica linguística e trazer à pauta a reflexão sobre a relação entre essa formação necessária de um leitor num contexto de crise e a política linguística.

PALAVRAS-CHAVE: política linguística; crise na leitura; formação do leitor. 


\section{Uma proposta desafiadora}

Há mais de uma década, vimos desenvolvendo pesquisas e orientando trabalhos voltados para questões relacionadas à compreensão leitora. Ao longo desse tempo, fomos alterando nosso foco. Desde a conceituação e a descrição do processo leitor em geral, partimos para enfocar as especificidades da leitura mediada por computador, em especial em tempos de internet, e as implicações dos diferentes gêneros textuais na atividade leitora. Começamos, agora, a preocuparmo-nos com a "crise na leitura", reiteradas vezes denunciada nas mídias e instituições, e com os constructos que os leitores, hoje inseridos numa sociedade da informação, globalizada e digitalizada, apresentam para o ato de ler.

Tudo isso, o fizemos e fazemos no âmbito da Linguística Aplicada, seguindo uma orientação teórica sociocognitiva. Quanto a nossas metodologias de estudo, tanto utilizamos abordagens documentais, quanto a observação de sujeitos. Adotamos, portanto, propostas empíricas e prioritariamente qualitativas para discutir e refletir sobre a atividade leitora como ato real e contextualizado.

A oportunidade de desenvolver este artigo abre um novo caminho nesse cenário de pesquisas. A leitura está intimamente ligada à língua, ao conhecimento linguístico, já que lemos textos verbais constantemente, e cada vez de forma mais diversificada, em nosso cotidiano. Sua aprendizagem, desenvolvimento e investigação, portanto, somam-se aos vários temas objetos de estudo da Linguística Aplicada. No entanto, não podemos, numa primeira apreciação, associá-la diretamente às questões que permeiam as discussões sobre políticas linguísticas. Haveria uma incompatibilidade entre as duas? Seria factível propor um olhar sobre as problemáticas da leitura desde uma perspectiva da política linguística? Acreditamos que sim.

Nosso desafio é, dessa forma, promover um tipo de aproximação que contribua para ambos os campos. O que trazemos aqui é uma proposta de reflexão: a discussão sobre a "crise na leitura" e a formação de leitores e de seus formadores como uma questão concernente ao âmbito da política linguística. Não estará, por certo, voltada para o registro ou o dialeto a serem ensinados e prestigiados. Nem tratará sobre da normatização, ou a respeito das decisões sobre a língua, seja ela oficial, materna, estrangeira, sobre sua internacionalização, ou situações de bilinguismo, por exemplo. Mas propomos discutir o lugar que a leitura, sua formação e 
desenvolvimento, parte do processo constante de letramento do indivíduo em sociedade, ocupam em nossa era da informação. E, como extensão, abordamos como uma política clara no âmbito linguístico se faz necessária para que tal letramento seja o mais eficaz e positivo possível, para os indivíduos e a sociedade.

Ao longo do artigo, apresentamos, para alcançar tais objetivos e responder a essas questões, três tópicos. São eles: uma breve contextualização sobre política linguística; a caracterização da leitura como processo sociocognitivo, com atenção a aspectos favorecidos pelas tecnologias da informação e comunicação; e a discussão, em si, da relação entre os dois temas, buscando uma síntese.

\section{Alguns breves aspectos sobre política linguística}

Podemos considerar que as preocupações e implicações políticas relacionadas à língua são antigas, embora não com o entendimento ou a clareza formal que hoje temos do tema. Luquetti e Moura (2009) exemplificam-nas com o surgimento de gramáticas, como a do sânscrito e a do latim clássico, ainda na Antiguidade. Segundo os autores, essas iniciativas associam-se a uma preocupação com a conservação das línguas e refletem a postura social de distinção hierárquica entre classes também no âmbito linguístico. Outro exemplo de uma visão política de língua associada ao Estado, porém ainda restrita à questão da conservação normativa, nas primícias da era moderna, podemos encontrar no prólogo da Gramática Castellana de Nebrija, publicada em 1492 (NEBRIJA, 1992). Em vários fragmentos desse texto introdutório de apresentação da gramática, o autor discorre sobre a importância de uma obra que garantisse a manutenção, uniformidade e estabilidade da língua, pelos séculos afora. Argumentava que serviria como documento de consulta, referência e ensino-aprendizagem da língua, materna ou estrangeira. Sua orientação política faz-se presente, também, na referência à expansão territorial do castelhano e na relação que seu autor estabelece entre a língua e o Estado, reiterada na dedicatória do trabalho à rainha Isabel de Castela. Podemos, ainda, inferir o movimento que conecta a produção acadêmica (escolástica) sobre a língua com a sua colocação a serviço do Estado, como documento de apoio.

Esse último aspecto também se vê nas atuais discussões de política linguística. No entanto, da Antiguidade e de 1492 até a atualidade, percorremos um longo caminho e vimos surgir a Linguística como ciência, expandindo as reflexões sobre a língua e seus usos. A preocupação com 
a conservação, a defesa e a normatização continua presente como objeto de interesse de política linguística, expressa, além de nas gramáticas, em manuais de escrita jornalística, livros didáticos e na escola (LUQUETTI; MOURA, 2009). Faz parte, contudo, de um amplo leque de temas em discussão nesse campo de estudo e envolve, igualmente, o caso de línguas minoritárias.

Embora possamos identificar no passado aspectos políticos nos exemplos citados e em outras iniciativas de instâncias públicas e/ou governamentais ligadas à língua, os termos "política" e "planificação linguística" surgem apenas nos anos 1950/1960. Inserem-se, naquele momento, no âmbito da Sociolinguística, voltados para os estudos de línguas em contato (SAAVEDRA; LAGARES, 2012).

Diferentes autores e trabalhos constroem a distinção entre ambos os termos, numa relação de subordinação. Enquanto as políticas linguísticas voltam-se para a "determinação de grandes escolhas relativas às relações entre as línguas e determinadas sociedades" (SAAVEDRA; LAGARES, 2012, p. 12), a planificação pode ser vista como "a política linguística posta em prática” (SAAVEDRA; LAGARES, 2012, p. 12). Mas esse planejamento linguístico é usado com várias acepções pelos diversos estudiosos, segundo seus agentes ou seus objetos. Assim, tanto se podem considerar como agentes as instituições normativas ligadas ao governo, quanto outros agentes sociais. E, no que se refere aos seus objetos, podem voltar-se para a padronização, o ensino-aprendizagem, a solução de problemas ligados à língua etc. (SAAVEDRA; LAGARES, 2012).

Hoje, o tema é estudado nos âmbitos da Sociolinguística, da Linguística Aplicada e do ensino de línguas. Tem duas dimensões, uma de análise e outra de intervenção, e envolve um conjunto de decisões governamentais (em sua maioria) sobre o status de línguas e registros na sociedade (SAAVEDRA; LAGARES, 2012; OLIVEIRA, 2001). Os estudos e as determinações abarcam tanto as línguas maternas quanto as estrangeiras. Pertencem, igualmente, à problemática da área a definição de línguas como oficiais, as línguas minoritárias, a internacionalização de uma língua, questões de monolinguismo e plurilinguismo, a defesa patrimonial da língua, a mestiçagem linguística (SAAVEDRA; LAGARES, 2012; OLIVEIRA, 2001; CASTRO, 2010; SILVA; SANTOS; JUSTINA, 2011).

Isso significa que os olhares sobre as questões das línguas as distribuem entre internas e externas, com relação às comunidades linguísticas observadas. No primeiro caso, temos debates que tratam da(s) língua(s) 
que existe $(\mathrm{m})$ em um determinado território: sua importância, o lugar que ocupa $(\mathrm{m})$ hierárquica e socialmente e suas funções. Mas que envolvem, também, a discussão sobre diferentes registros; direito à pluralidade; respeito às diferenças, ao conhecimento de distintas formas de expressar-se em cada situação, à ampliação de horizontes linguísticos; tratamento escolar das questões sobre língua. No segundo caso, trata-se do espaço cultural, comunicativo, científico, diplomático e comercial que uma língua pode ocupar no cenário internacional.

Nesse particular, Castro (2010) polemiza tanto as situações de estrangeirismo de uma língua (nesse caso, a portuguesa) dentro de seu próprio território, já que falada como oficial por pessoas de diferentes nacionalidades, quanto o direito a que seja também uma metalíngua. $\mathrm{Ou}$ seja, que seus usuários possam empregá-la para falar dela mesma, estudá-la e difundi-la internacionalmente, não só como uma língua estrangeira mas como veículo de divulgação de saberes científicos e obras literárias. Todos esses domínios, por assim dizer, são (ou deveriam ser) alvo de deliberações institucionais no âmbito estatal, regulados por leis internas e acordos internacionais.

Nesse contexto, ganham importância tanto os linguistas e as associações científicas, quanto as escolas e professores e a sociedade como um todo. Decisões governamentais são, muitas vezes, fruto de discussões e informações fornecidas por estudos científicos, embora as haja determinadas por fatores políticos e econômicos (SAAVEDRA; LAGARES, 2012). As escolas (e seus professores, por extensão) podem ser tanto espaços de perpetuação de preconceitos e cerceamentos linguísticos, quanto de renovação, pluralidade e utilização crítica, consciente e multicultural das línguas. Naturalmente, o desejável é que ocupem a segunda posição. Por fim, a sociedade pode, aberta a essas questões, refletir sobre sua(s) própria(s) língua(s), suas utilidades, funções e status, reivindicando, de governantes e instituições, atitudes e legislação específicas, coerentes e valorizadoras de todas as manifestações linguísticas reais e autênticas.

Em função do foco escolhido para este artigo, optamos por destacar, no que se refere à questão da política linguística, a relação entre legislação e ações no campo educacional. Isso porque, entre outros, o ensino de línguas é um dos aspectos privilegiados nos estudos de política linguística e, dentro dele, o trabalho com leitura e escrita, conforme discutem pesquisas de Caribaux (2015) e Bima e Gambini (2015).

Saavedra e Lagares (2012) apresentam em seu artigo um breve, 
mas variado em termos de objetos de interesse, panorama da legislação brasileira (ou atos de política linguística) que se ocupa de questões sobre as línguas. O primeiro documento citado é a Constituição da República Federativa do Brasil, de 1988, alterada em 1994. Também são mencionadas leis (ou projetos de lei) sobre o Acordo Ortográfico do português; diretrizes da educação nacional; aspectos sobre tradução, dublagem e legendagem; assuntos indígenas; oferta de língua espanhola no ensino médio, de matrícula facultativa para os alunos; promoção e defesa da língua portuguesa. Os autores, no entanto, reiteram sua avaliação sobre a escassez "de políticas linguísticas e educacionais para o ensino de línguas no país, considerando as diferentes situações de contato linguístico que aqui coexitem" (SAAVEDRA; LAGARES, 2012, p.20).

Em nossa constituição (BRASIL, 1988), o artigo 13 explicita que o português é o idioma oficial do país. E, em seu artigo $210, \S 2^{\circ}$, ela define que "o ensino fundamental regular será ministrado em língua portuguesa, assegurada às comunidades indígenas também a utilização de suas línguas maternas e processos próprios de aprendizagem." Tal artigo esclarece que é dada a primazia, no sistema escolar brasileiro, à língua oficial, reconhecendo-se o direito das comunidades indígenas ao uso educacional de suas línguas maternas. Apesar disso, enfatiza-se, no artigo 215, a garantia ao pleno exercício dos direitos culturais de todos os grupos que participaram/participam do "processo civilizatório nacional" (BRASIL, 1988, Art. 215, $\left.\S 1^{\circ}\right)$. Ou seja, constitucionalmente, não há um reconhecimento pleno da realidade plurilinguística do Brasil, nem referências às situações de contato com línguas de fronteiras ou de imigrantes em nosso território.

A Lei de Diretrizes e Bases da Educação Nacional, Lei $n^{\circ}$ 9.394, de 20 de dezembro de 1996 (BRASIL, 1996), defende em seu Artigo 3º, em termos gerais, o respeito à liberdade e apreço à tolerância, bem como considera a diversidade étnico-racial. Mas, ao tratar, no capítulo II, da Educação Básica, dos currículos, desde a educação infantil, até o ensino médio, especifica, no Art. $26, \S 1^{\circ}$, obrigatoriamente o estudo da língua portuguesa no seu núcleo comum. Destaca, ainda, no Art. $32, \S 3^{\circ}$, que o ensino fundamental regular será ministrado nessa língua, resguardado o direito de utilização das línguas maternas das comunidades indígenas (reiterado no Art. 78, inciso I), tal como já determinado na constituição. Quanto ao ensino médio, a língua portuguesa é citada no Art. 36, inciso I "como instrumento de comunicação, acesso ao conhecimento e exercício da cidadania". 
As línguas estrangeiras são citadas na LDB 9.394/96 (BRASIL, 1996), nos seguintes artigos:

a) Art. 24, inciso IV, junto a outras disciplinas, esclarecendo a possibilidade de agrupar-se alunos de séries distintas cujo nível de adiantamento na matéria seja equivalente, formando turmas específicas;

b) Art. 26, $\S 5^{\circ}$, informando que há obrigatoriedade de inclusão de ao menos uma língua estrangeira moderna no ensino fundamental, na parte diversificada do currículo, segundo a escolha da comunidade e possibilidade institucional;

c) Art. 36, inciso III, definindo a inclusão de duas línguas estrangeiras modernas no ensino médio, uma obrigatória, escolhida pela comunidade escolar, e outra optativa, segundo as disponibilidades.

Em 2005, promulgou-se a lei 11.161 (BRASIL, 2005), que define a oferta obrigatória, por parte das escolas, mas com matrícula facultativa para os alunos, da língua espanhola no ensino médio. Tal lei motivou-se, entre outras razões, pela integração do Brasil com os países do Mercosul, cuja língua oficial é o espanhol. Mas a situação de intercâmbio cultural, político, econômico e a proximidade geográfica (fronteiriça) de nosso país com a América Latina, prioritariamente composta de países hispano-falantes, constitui uma clara motivação para defender essa medida.

Como se pode perceber, não há, de fato, muitas leis voltadas para as questões específicas e complexas da situação linguística brasileira. E a existência destas aqui citadas não garante, necessariamente, a implementação de planejamentos políticos e ações que assegurem sua efetiva concreção. Tampouco assegura o atendimento à diversidade interna e às relações externas no âmbito linguístico. Da mesma forma, o que existe não oferece detalhes sobre as especificidades dos usos das línguas, seu status, ou questões como o preconceito linguístico ou o plurilinguismo.

\section{Caracterização do processo leitor na era da in- formação}

Falar sobre leitura abre-nos muitas possibilidades. Podemos pensá-la como atividade social, presente em nosso cotidiano sob diferentes formas. É possível abordá-la teoricamente a partir de seu componente cognitivo, ou discutir sua inserção como prática letrada no contexto das sociedades ao longo dos tempos. Se pensarmos no mundo em que vivemos hoje, na era da informação, dos avanços informáticos e digitais, precisamos refletir sobre leitura sem nos afastarmos dos temas das tec- 
nologias da informação e comunicação, da internet e dos hipertextos. Somemos a tudo isso as críticas, que vêm sendo veiculadas nas mídias e abordadas nos meios escolares, sobre a debilitação do desempenho leitor dos jovens. E, como consequência de tais preocupações, o propósito de examiná-la como objeto de ensino-aprendizagem.

Toda essa diversidade de aspectos aponta para a abrangência do tema. Permite-nos, também, inferir uma multiplicidade de áreas do conhecimento que podem interessar-se em estudá-lo, sob diversas abordagens teóricas e metodológicas.

Partimos, aqui, do pressuposto de que a leitura é uma atividade complexa, não natural, mas social e cultural, parte do processo permanente de letramento, portanto, algo que deve ser aprendido e desenvolvido. Também assumimos seu caráter cognitivo, devido ao conjunto de conhecimentos que demanda e estratégias que movimenta (PERFETTI; LANDI; OAKHILL, 2013; VERGNANO-JUNGER, 2015a; 2015b.). Optamos, então, por uma abordagem teórica sociocognitiva, analisando os processos leitores tanto considerando suas implicações sociais, quanto o processamento multidirecional da informação (VERGNANO-JUNGER, 2015a).

No que se refere à questão social, é preciso observar e discutir o ato leitor em contexto. São relevantes os indivíduos envolvidos no processo tanto de escrever, quanto de difundir e ler; seus objetivos, necessidades e motivações, e as coerções a que estão submetidos. Cada atividade social que envolva textos escritos terá uma inserção própria, segundo o espaço e o tempo, utilizará gêneros textuais determinados e demandará atitudes que estejam conformes com a situação (NUNES, 2005; VERGNANO-JUNGER, 2015a; 2015b).

Se pensamos, por sua vez, no componente cognitivo, temos que considerar que, durante a tarefa de compreender, passamos por diferentes níveis. Primeiro apreendemos palavras, sintagmas, frases, fragmentos, textos, identificando unidades linguísticas. Essa etapa decodificadora não conclui a leitura, mas é importante para fornecer elementos com os quais o leitor trabalha para negociar significados e atribuir sentidos. A seguir, passamos a níveis mais complexos, utilizando estratégias mais profundas do que o simples reconhecimento: comparamos, inferimos, avaliamos, controlamos o processo, selecionando o que serve à compreensão e abandonando o inadequado (PERFETTI; LANDI; OAKHILL, 2013).

Para que tais tarefas se desenvolvam, usamos nossa capacidade cognitiva, ativando conhecimentos armazenados na memória, selecio- 
nando e aplicando as melhores estratégias para a solução de problemas. Ao fazê-lo, realizamos um movimento multidirecional, reunindo dados de naturezas muito diversas, dispersos em diferentes fontes, comparados e conjugados segundo cada situação e necessidade. Também os insumos socioculturais entram em jogo, modulando nossa cognição. Justamente por isso, não temos leituras totalmente iguais de um mesmo texto, embora haja coerções que não permitem que essas leituras sejam, ao mesmo tempo, adequadas e infinitas. Essa complexidade e essa pluralidade de caminhos e insumos é que nos levaram a constatar o processamento multidirecional da informação na leitura e, conforme já afirmamos, o procedimento talvez mais indicado para os desafios de leitura na atualidade (VERGNANO-JUNGER, 2015a).

E, por que destacar os desafios leitores no mundo de hoje, relacionando-os a uma proposta multidirecional de leitura? Os avanços informáticos possibilitam-nos uma versatilidade, rapidez, interação e abrangência comunicativas, provavelmente, inéditas na história da humanidade (CASSANY, 2012). Podemos conversar em tempo real com pessoas do outro lado do planeta com alguns cliques. Ante uma dúvida, rapidamente recorremos a consultas por buscadores virtuais desde nossos aparelhos celulares, em praticamente qualquer lugar. Enviamos fotos, mensagens de texto e de voz, vemos vídeos, ouvimos música, compartilhamos dados e ideias, participamos de enormes redes sociais, contatamos conhecidos e desconhecidos com igual facilidade. Tudo isso ao alcance dos dedos.

Essa realidade permite o surgimento de gêneros textuais novos ou reinventados/repaginados a partir dos já conhecidos e familiares. Usos de linguagem alteram-se, criam-se abreviaturas, formas de marcar aspectos gramaticais e pragmáticos são inventadas, mesclam-se linguagens (em especial as imagéticas com as verbais). Os textos não são fechados, seus limites podem não ser previamente (re)conhecidos, já que se enlaçam numa construção hipertextual (CASSANY, 2012; VERGNANO-JUNGER, 2015a; 2015b). Embora os hipertextos não sejam uma novidade completa (pensemos nas notas de rodapé e nos sumários), com os recursos digitais, alcançaram dimensões novas de rapidez e imediatismo no acesso. O leitor passa a ser, em certa medida, (co)autor dos textos que compõe a partir de sua navegação (RAMÍREZ LEYVA, 2005).

Ao lado de tantas (aparentes) vantagens, as construções hipertextuais geraram, igualmente, certa fragmentação, um "espalhamento" das ideias, dos dados e das informações. Isso pode, como ressaltou Marcuschi 
(2001), ocasionar um stress cognitivo no leitor, fazendo-o perder-se durante sua leitura, entre intermináveis janelas e opções. Outros problemas de compreensão que podemos identificar na comunicação via internet nascem pelo contato intercultural, por um lado, e pela facilidade de publicação, por outro.

Naquele caso, ao interagirmos com pessoas de diferentes culturas e línguas, de lugares distantes, muitas vezes sem conhecimento mútuo (pessoal e cultural), pode haver incompreensão de detalhes e mal-entendidos, mesmo quando as palavras são apreendidas no seu sentido literal (CASSANY, 2012). Já a liberdade de publicar pensamentos, ideias, ideologias, produções próprias ou alheias, entre outros, facilita tanto a imprecisão quanto a divulgação de fatos incorretos, como as apropriações indevidas de materiais de outros, causando problemas autorais (CASSANY, 2012). Nessas situações, é requerido do leitor um trabalho de seleção e avaliação mais apurado, bem como a negociação de sentidos nos casos de choque intercultural.

Se observarmos atentamente, chegamos à conclusão de que, ainda hoje, grande parte do material circulante na internet é verbal e escrito. As interações assíncronas, por exemplo, por meio de fóruns e redes sociais, envolvem textos verbais, mesmo admitindo-se o crescimento da inserção de fotos, imagens e vídeos. Isso implica, portanto, leitura. E tal atividade leitora envolve a ativação de um enorme volume de conhecimentos e de estratégias. Também demanda grande controle, inclusive para minimizar os impactos do referido stress cognitivo, dos choques interculturais e das dúvidas sobre a idoneidade e a precisão de fontes e autores. Por tais razões, defendemos a íntima relação entre a proposta de uma leitura multidirecional e a interação do leitor com os textos que acessa e manipula no meio digital.

Fazemos apenas uma ressalva, nesse particular. Nem todos os textos presentes na internet ou em nossos computadores deveriam ser, estrito senso, considerados como digitais. Muitos são apenas digitalizações de materiais previamente produzidos em meios impressos, ou seguindo seu modelo. Consideramos como eminentemente digitais os textos que possuem uma organização hipertextual, com links e possibilidades de navegação interna e/ou externa a eles. Também identificamos como um perfil característico de diferentes gêneros textuais do meio digital a presença de multimodalidade. Ou seja, da junção de texto verbal e não verbal, seja este visual ou sonoro (VERGNANO-JUNGER, 2015a; 2015b). 
Em resumo, no mundo de hoje, mesmo que as vivenciando em novos suportes e sob novas formas, estamos imersos em leituras. Em especial, o sentimos nas sociedades urbanas, altamente informatizadas e letradas, embora mesmo os analfabetos tenham consciência dos papéis do universo leitor. Pela própria natureza dos textos divulgados e criados no ambiente virtual, os leitores da atualidade precisam desenvolver estratégias de inferência, seleção, avaliação e controle refinadas e aguçadas. No entanto, parecemos estar numa etapa de transição, na qual coexistem muitas manifestações ainda oriundas da cultura impressa/livresca com as novas criações digitais, e não temos plena dimensão do que o futuro nos reserva. Por isso, o leitor dessa fase não pode limitar-se a nenhuma das duas realidades. Deve procurar transitar por ambas (com igual destreza?), para atender plenamente às demandas sociais relacionadas à cultura letrada.

\section{Crise na leitura, formação de leitores e uma po- lítica linguística necessária}

A exigência que apontamos ao final do tópico anterior parece-nos ser um dos pontos nevrálgicos para uma reflexão sobre a crise na leitura. Mas o que podemos inserir nesse universo da atividade leitora para definir o que deve ser o ato de ler e como devem ser formados e incentivados os leitores?

Ramírez Leyva (2005) apresentou quatro situações de leitura, consideradas pela Organização para a Cooperação e o Desenvolvimento Econômico (OCDE), que promove o Programa para a Avaliação Internacional de Estudantes (o PISA), em seu instrumento de avaliação. São a leitura para: (a) o uso privado/ pessoal; (b) o uso público; (c) o trabalho e (d) a educação. A primeira estaria mais vinculada ao prazer, já que envolve lazer e curiosidade pessoais. A pública relaciona-se ao compartilhamento de informações, como relatórios ou conferências. A de trabalho vincula-se à realização de tarefas. A de educação, também chamada didática ou escolarizada, voltada ao aprendizado de conteúdos, selecionados pelo professor e pelas instâncias escolares.

Sobre esta última, Domingo Argüelles (2005) apresenta incisivas críticas. $\mathrm{O}$ autor defende que se tornar leitor, no sentido mais completo e amplo do termo, está mais relacionado ao prazer, à fruição, do que à formação de um hábito. Considera a proposta escolar autoritária, desestimulante e, em certa medida, contraditória. Isso porque muitos dos agentes formadores ou defensores da leitura canônica como imprescindível forma 
de inserção e ascensão social sequer a praticam regular ou prazerosamente. Além disso, relaciona a referência à "formação de hábito leitor" a uma atitude impositiva, rotineira, monótona, mecânica, desprovida de criatividade e, consequentemente, de prazer e eficácia.

A discussão de Domingo Argüelles enfatiza os textos literários e como eles se transformam em meros exercícios ou instrumentos de avaliação (diríamos, "medida") no sistema escolar. Mas, olhando à nossa volta e inspirados pelas situações de leitura selecionadas como parâmetros para a avaliação no PISA, temos que admitir que se lê muito mais do que textos literários. Portanto, é razoável argumentar que não deveríamos nos fixar apenas neles para afirmar que hoje se lê pouco, ou mal.

Segundo Petrucci (1999), enquanto houver atividade de escrita, haverá leitura. E parece inegável que houve um crescimento nas finalidades, usos (e, por que não dizer, usuários) e formas da escrita ao longo da história. A questão, então, parece-nos, deve deslocar-se para "como" e "de que tipo" será a leitura daqui para adiante e como devemos proceder com relação a ela. O mesmo autor (1999) destaca que as preocupações partem de um certo rechaço ao cânone, que se observa entre os leitores atuais. $\mathrm{O}$ leitor estaria assumindo uma atitude mais livre e rebelde, voltada para leituras de massa, que compartilham seu interesse, tempo e espaço com outros veículos de comunicação, como a televisão, por exemplo.

Se pensarmos na expansão dos meios digitais, em especial, na popularização do acesso à internet, não citados por Petrucci em seu artigo, temos que admitir que seu impacto intensifica as discussões. Não podemos ignorar que, havendo escrita, sim, há leitura! E que cada vez que as pessoas acessam jornais digitais, redes sociais, buscadores, e-mails, blogs etc., estão lendo. Assim como leem quando procuram a comida no cardápio, ou informações sobre a saída de um ônibus. No entanto, claramente, trata-se de diferentes leituras, com níveis variados de complexidade. E sua diversidade está nos gêneros textuais lidos, suportes de seus textos, nas situações que motivam a atividade leitora e nos próprios leitores. Afinal, lê-se para buscar informação, saciar a curiosidade ou por algum interesse pessoal que se queira aprofundar, para estudar, pesquisar, conhecer novas realidades, refletir sobre si e o mundo, resolver problemas, entrar em contato com outras pessoas, relaxar ou sentir prazer, entre uma infinidade de possibilidades. Não podemos ser tão ingênuos ou simplistas a ponto de acreditar que alguma dessas atividades não constituiria uma forma de leitura, ou que todas ocorreriam de maneira idêntica. 
Posto isso, onde inseriríamos a questão da política linguística? Tratar sobre língua não se limita à sua descrição, situação, variações, mas, também, a como ela marca nossas identidades e o que fazemos com e por meio dela. Nossa explanação até o momento tem mostrado como estamos imersos em leituras. Entre as várias áreas do saber que se ocupam de seu estudo, direta ou indiretamente, encontra-se a Linguística Aplicada. De modo particular, as reflexões de seus pesquisadores têm-se voltado para o ensino-aprendizagem de leitura, seja em língua materna, seja na estrangeira. Segundo Rajagopalan (SILVA; SANTOS; JUSTINA, 2011) e Saavedra e Lagares (2012), o campo do ensino de línguas, no âmbito da Linguística Aplicada, também faz parte das preocupações e manifestações da política linguística. Eis aí a nossa ponte possível.

Quando abordamos o ensino de leitura, pensamos não só nos alunos, mas na formação de seus professores. Assim como já havia destacado Domingo Argüelles (2005), Perissé e Matos (2011) reafirmam a importância de que os professores sejam efetivos leitores. Sem que se percebam neles nem o prazer, nem a proficiência em leitura, exercerão "uma prática docente que tem como protagonistas pseudoleitores" (PERISSÉ; MATOS, 2011, p.50). E isso, naturalmente, funcionaria como um contraexemplo, desestimulando, ainda mais, os alunos já submetidos a propostas de ensino não significativas, impositivas e mecânicas. Outro aspecto que enfatizam esses autores é a denúncia de uma prática leitora meramente instrumental, que não promove oportunidades para desenvolver o pensamento, não é desafiadora. Ramírez Leyva (2005) também discute explicações para a dificuldade de compreensão e atribuição de sentidos pelos jovens aos textos lidos. Reforça a constatação de que há uma cultura pedagógica que transformou a leitura em "una práctica para la acumulación de datos e información y (...) los libros meros recipientes de datos para ser repetidos, sin que exista análisis"' (RAMÍREZ LEYVA, 2005, p. 105). Em suma, defende que esse modelo pedagógico e cultural distorceu a prática pedagógica relacionada à leitura, priorizando aspectos práticos, utilitários, voltados para atividades produtivas.

Consideramos, contudo, que a questão não deveria, necessariamente, dicotomizar a problemática em leituras criativas, prazerosas e reflexivas versus leituras utilitárias, voltadas para dados e limitadas. Dependendo dos objetivos, da bagagem de conhecimentos acionada, das estratégias utilizadas e do trabalho de (re)construção de sentidos que promova o leitor, talvez fosse possível encontrar caminhos que demonstrassem critici- 
dade e profundidade na leitura, mesmo em textos inusitados. Parece-nos, no final, que o desejável é promover o crescimento desse sujeito leitor, de sua capacidade de aprofundamento na interpretação e de sua liberdade e criticidade nas escolhas.

Em termos de política linguística, portanto, defendemos que o primeiro ponto a definir claramente é o que se entende como leitura no mundo de hoje. A partir daí, caberia determinar quais são os requisitos para que ela se desenvolva de modo a contribuir para o letramento continuado dos indivíduos. Isso oferecerá subsídios para que se proponha um planejamento para seu ensino de modo a contemplar toda a sua complexidade e abrangência.

Sigamos o raciocínio de preocupação dos estudiosos em política linguística com a pluralidade e o multiculturalismo, e consideremos a diversidade de meios que atualmente difundem textos e propiciam a leitura. Teríamos, então, que admitir que qualquer política linguística voltada para a formação de formadores de leitores e de leitores em si deveria reconhecer alguns princípios:

- os cânones são mutáveis, segundo o tempo e as sociedades que os definem;

- lê-se não apenas textos literários, mas qualquer material que tenha sido escrito;

- $\quad$ os textos não apenas se compõem de palavras (textos verbais) mas de um conjunto que admite a presença de outras linguagens, como a imagética;

- a estrutura dos textos, com o advento da internet, potencializa a hipertextualidade e a multimodalidade, o que, de alguma forma, altera os caminhos de leitura típicos da estrutura dos livros impressos;

- as leituras são situadas, ou seja, cada situação, gênero textual, assunto, suporte, necessidade e objetivo altera o contexto em que ela ocorre, demandando conhecimentos e estratégias apropriados a cada caso.

Essas assertivas acompanham conclusões, descobertas e teorias sobre o processo leitor e sobre seu estudo como atividade social. Além de complexo, ele é plural. Não exatamente no sentido de haver infinitas leituras para cada texto, mas no de reconhecer que tampouco há apenas uma única, e que ler se ajusta às circunstâncias e utiliza vários insumos.

Partindo dessas premissas, a crise na leitura teria que ser redimen- 
sionada. O problema deixa de residir no que (não) se lê, ou no quanto (não) se lê, para recair sobre o como se está lendo, quando se está lendo. E, também, se sabemos selecionar as atitudes adequadas aos vários contextos de leitura. É desejável que haja leitores que saibam apreciar as obras literárias e sintam prazer em lê-las. Mas também é importante que as pessoas saibam avaliar uma publicidade, por exemplo, sem se deixar simplesmente levar pelo seu apelo, ou desenvolver uma pesquisa, fazendo dialogar criticamente várias fontes. $\mathrm{Ou}$, ainda, que consigam selecionar informação, avaliá-la, validá-la e utilizá-la, incorporando-a à sua bagagem cognitiva e cultural.

Não podemos deixar que nossas decisões se pautem pelo preconceito contra as escolhas de cada leitor. Elas devem orientar-se pela competência em usar a leitura para aquilo que ela demandar em cada momento específico. Tal como as discussões sobre que língua ensinar na escola e como respeitar a diversidade linguística dos alunos, cabe pensar diretrizes que ajudem a formar leitores autônomos e críticos. Iniciativas que lhes permitam sentir prazer ao ler e satisfação com a sua tarefa leitora bem realizada, com o alcance de seus próprios objetivos e com a autonomia em suas decisões.

\section{Atando os fios do atual tecido leitor}

No âmbito da Linguística Aplicada, reservamos um espaço para discutir a leitura e como ela pode ser ensinada de modo a contribuir para o letramento de cidadãos que vivam plenamente em sociedade. Essa plenitude passa tanto por realizar as mais diversas atividades mediadas pela palavra escrita, quanto por conseguir alcançar o prazer com a leitura ou exercer o pensamento reflexivo. Tudo isso sempre com capacidade crítica de escolha e avaliação do que se vai ler, quando, como e para quê.

Tradicionalmente, a escola tem papel de destaque na formação de leitores. No entanto, tem-se arraigado em modelos canônicos, rígidos, olhando unilateralmente para o aluno e para suas necessidades e demandas. Cabe aplicar tudo o que vem sendo estudado e produzido no contexto acadêmico à elaboração de políticas linguísticas que rompam com essa estagnação e com o mito da "profusão de não leitores".

As pessoas leem. Talvez até de forma mais estendida e diversificada, hoje, do que ao longo da história. No entanto, nem sempre o fazem de modo a alcançar plenamente seus próprios objetivos. Faltam orientações para utilizar adequadamente estratégias cognitivas e os conhecimentos 
que já possuem ou que podem acessar, para reconhecer a relevância do contexto social em que a leitura ocorre. Mas também faltam a liberdade, a autonomia e a confiança para fazer escolhas (e avaliá-las criticamente) e o respeito e a valorização dos caminhos escolhidos.

Hoje a escola não é o único espaço de aprendizagem. Mas pode sê-lo para discussão e desenvolvimento de olhares críticos. Trata-se não só de uma decisão acadêmica, mas de uma decisão política. Trata-se de decidir observar o que ocorre à nossa volta, considerar os trabalhos que discutem tais questões e compor um planejamento que contribua para a mudança.

\section{READING CRISIS AND READER'S EDUCATION: A MAT- TER OF LANGUAGE POLICY?}

\section{ABSTRACT}

Researchers, governmental agencies, and offices of evaluation have been focusing their attention on the so-called "reading comprehension crisis" in Brazil. Besides, a discussion about reader's education and the causational role of the school emerges from this midst. Likewise, the Internet and other digital technologies with their own texts and languages are often associated with the problem. In the last few years, we have been studying the aspects involved in reading comprehension with emphasis on how it relates to the digital world. Even though the discussions around the reading comprehension crisis take place under the scope of Education, we approach it under the framework of the socio-cognition within Applied Linguistics. Thus, in this paper, we propose to tackle this issue under the light of the Linguistics and add to the discussion the relationship between the necessary steps to educate the reader in the scenario of crisis and language policy.

KEYWORDS: language policy; reading crisis; reader education. 


\section{REFERENNCIAS}

BIMA, F. GAMBINI, A. F. Lectura y escritura como prácticas sociales interconectadas: un medio para la integración. In: REGUERA, A. (comp.) Actas del VII Encuentro Internacional de Investigadores de Políticas Lingüísticas. Córdoba: Facultad de Letras y Secyt, Universidad Nacional de Córdoba, Asociación de Universidades Grupo Montevideo - Núcleo Educación para la Integración, 2015. p. 80-88.

BRASIL. Lei 9.394 - Diretrizes e Bases da Educação Nacional. Brasília: Ministério da Educação - MEC, D.O. de 23/12/1996, 1996.

. Constituição da República Federativa do Brasil de 1988. Brasília: D.O.U 191-A de 05/08/1988.

. Lei 11.161/2005 - dispõe sobre o ensino da língua espanhola. Brasília: Ministério da Educação - MEC, D.O.U de 08/08/2005, 2005.

CARIBAUX, S. M. Políticas lingüísticas profundas y políticas lingüísticas superficiales en PLE. In: REGUERA, A. (comp.) Actas del VII Encuentro Internacional de Investigadores de Políticas Lingüísticas. Córdoba: Facultad de Letras y Secyt, Universidad Nacional de Córdoba, Asociación de Universidades Grupo Montevideo - Núcleo Educación para la Integración, 2015. p. 107-114.

CASSANY, D. En_línea: leer y escribir en la red. Barcelona: Anagrama, 2012.

CASTRO, I. As políticas linguísticas do português. In: Textos selecionados, XXV Encontro Nacional da Associação Portuguesa de Linguística, Porto: APL, 2010, pp. 65-71.

DOMINGO ARGÜELLES, J. Sobre la mitología bienintencionada de la lectura. Tres apostillas al libro ¿Qué leen los que no leen? In: RAMÍREZ LEYVA, E.M. (comp.) Lectura: pasado, presente y futuro. Memoria del Seminario Lectura: pasado, presente y futuro. México: UNAM, Centro Universitario de Investigaciones Bibliotecológicas, 2005. p.86-97.

LUQUETTI, E. C. F. MOURA, S. A. de. Políticas linguísticas na escola: a conscientização linguística na formação do professor. Anais IV ENLETRARTE; Encontro Nacional de Professores de Letras e Artes - Mediando linguagens, 'entrecedendo' olhares. Campos: Instituto Federal de Educação, Ciência e Tecnologias Fluminense, 2009. Disponível em: http://essentiaeditora.iff.edu.br/index. php/enletrarte/article/view/1762/946 Acesso em: 20/05/2016.

MARCUSCHI, Luiz Antônio. O hipertexto como novo espaço de escrita em sala de aula. In: Linguagem e Ensino, vol. 4, nº 1, 2001, p. 79-111.

NEBRIJA, E. A. de. Gramática Castellana. Madrid: Fundación Antonio de Nebrija, 1992. 
NUNES, Myriam Brito Corrêa. Visão Sócio-interacional de Leitura. In: SALIÉS, T. G. (Org.) Oficina de Leitura Instrumental: Planejamento e Elaboração de Materiais; coletânea de documentos. Rio de Janeiro: IPEL/PUC-Rio, 2005.[Artigo 02; publicação em CD-ROM]

OLIVEIRA, G. M. Políticas Linguísticas Como Políticas Públicas. In: BERTUSSI, G. T. ; OURIQUES, N. D. (Coordenadores). (Org.). Anuário Educativo Brasileiro: Visão Retrospectiva. São Paulo: Cortez, 2001, p. 313-333.

PERFETTI, C. A. LANDI, N. OAKHILL, J. A aquisição da habilidade de compreensão da leitura. In: SNOWLING, M. J.; HULME, C. (Orgs.) A ciência da leitura. Porto Alegre: Pensa, 2013. p. 245-265.

PERISSÉ, G.; MATOS, N. S. de. Leitura e professores: uma relação em crise. International Studies on Law and Education, 7, jan-jun 2011, CEMOOrOc-Feusp/ IJI-Univ. do Porto. Disponível em: http://hottopos.com/isle7/49-54Gabriel.pdf Acesso em: 08/10/2015.

PETRUCCI, A. Ler por ler: um futuro para a leitura. In: CAVALLO, G.; CHARTIER, R. (orgs.) História da leitura no mundo ocidental, v.2. São Paulo: Ática, 1999.

RAMÍREZ LEYVA, E. M. La lectura en los tiempos de Internet. In: RAMÍREZ LEYVA, E. M. (comp.) Lectura: pasado, presente y futuro. Memoria del Seminario Lectura: pasado, presente y futuro. México: UNAM, Centro Universitario de Investigaciones Bibliotecológicas, 2005. p. 98-114.

SAAVEDRA. M. M. G.; LAGARES, X. C. Política e planificação linguística: conceitos, terminologias e intervenções no Brasil. Gragoatá. Publicação dos Programas de Pós-Graduação do Instituto de Letras da Universidade Federal Fluminense. Niterói, n. 32, 1 sem. 2012, p. 11-27.

SILVA, K. A.; SANTOS; L. I. S.; JUSTINA, O. D. Entrevista com Kanavillil Rajagopalan: ponderações sobre linguística aplicada, política linguística e ensino-aprendizagem. Revista de Letras Norte@mentos - Revista de Estudos Linguísticos e Literários. Edição 08 - Estudos Linguísticos 2011/02. Disponível em: http://projetos.unemat-net.br/revistas_eletronicas/index.php/norteamentos e http://www. alab.org.br/pt/destaque/155-entrevista-com-kanavillil-rajagopalan-ponderacoes-sobre-linguistica-aplicada-politica-linguistica-e-ensino-aprendizagem. Acesso em: 23/05/2016.

VERGNANO-JUNGER, Cristina. Letramento na era da informação: a questão da leitura em meio digital na pesquisa científica universitária. Matraga. Rio de Janeiro, v.22, p.56 - 75, $2015 \mathrm{a}$.

. Leitura na sociedade da informação e formação de professores: um olhar 
sociocognitivo. In: Linguagem: Teoria, Análise e Aplicações, v. 8. [meio digital]. Rio de Janeiro: Programa de Pós-graduação em Letras/ UERJ, 2015 b.

\section{NOTA}

${ }^{1}$ Tradução livre da autora: transformou a leitura em "uma prática para a acumulação de dados e informação e (...) os livros em meros recipientes de dados a serem repetidos, sem que exista análise".

Recebido em: 07 de junho de 2016

Aceito em: 19 de junho de 2016 